\title{
Did the 2009 American Recovery and Reinvestment Act affect Dietary
}

\author{
Intake of Low-Income Individuals? ${ }^{1}$
}

\author{
Geetha Waehrer \\ Pacific Institute for Research and Evaluation
}

Partha Deb

Department of Economics

Hunter College, CUNY

Sandra L. Decker

National Center for Health Statistics

\footnotetext{
${ }^{1}$ This research was partly funded through a Research Innovation and Development Grant in Economics (RIDGE) from the U.S. Department of Agriculture's (USDA) Economic Research Service administered through the Institute for Research on Poverty (IRP) at the University of Wisconsin-Madison. The authors thank participants at the April 2013 IRP-USDA RIDGE Workshop and the December 2013 USDA RIDGE meetings for their detailed and useful comments. All remaining errors are the responsibility of the authors. Most of this work was completed while Sandra Decker was at the National Center for Health Statistics of the Centers for Disease Control and Prevention. The work was completed while Sandra Decker was with the Agency for Healthcare Research and Quality. The views and opinions expressed herein are those of the authors and do not necessarily reflect those of the Institute for Research on Poverty, the United States Department of Agriculture, the Agency for Healthcare Research and Quality, or the Centers for Disease Control and Prevention.
} 


\begin{abstract}
This paper examines the relationship between increased Supplemental Nutritional Assistance Program (SNAP) benefits following the 2009 American Recovery and Reinvestment Act (ARRA) and the diet quality of individuals from SNAP-eligible compared to ineligible (those with somewhat higher income) households using data from the 2007-2010 National Health and Nutrition Examination Survey. The ARRA increased SNAP monthly benefits by $13.6 \%$ of the maximum allotment for a given household size, equivalent to an increase of $\$ 24$ to $\$ 144$ for one-to-eight person households respectively. In the full sample, we find that these increases in SNAP benefits are not associated with changes in nutrient intake and diet quality. However, among those with no more than a high school education, higher SNAP benefits are associated with a $46 \%$ increase in the mean caloric share from sugar-sweetened beverages (SSBs) and a decrease in overall diet quality especially for those at the lower end of the diet quality distribution, amounting to a 9 percent decline at the 25 th percentile.
\end{abstract}




\section{Introduction}

The great recession of 2007-2009 was the longest contraction of the US economy since the depression of the 1930s. Persistent unemployment and falling incomes strained family budgets and depressed consumer spending, including a reduction in food expenditures (Kumcu and Kaufman, 2011). The American Recovery and Reinvestment Act of 2009 (ARRA) aimed to provide temporary relief to families affected by these unfavorable economic conditions, including a boost to the Supplemental Nutritional Assistance Program (SNAP), the largest food assistance program in the country. As a result of the ARRA, the median value of SNAP benefits in participating households rose by approximately $17 \%$ and eligibility rules were relaxed (Nord and Prell, 2011a). - Enrollment in SNAP rose by 53\% from 2007 to 2010 and peaked in 2013 with over 47 million people enrolled in the program (USDA, 2014b).

Recent research has documented that the ARRA expansions in SNAP (formerly known as food stamps) benefits have improved food security and increased food expenditures among lowincome families (Nord and Prell, 2011b). However, little is known about the impact of the benefit expansion on diet quality of recipients. Although the intent of the ARRA increase in SNAP benefits may have been to maintain food budgets during an economic downtown, such information on the effects of increased benefits on diet quality may be especially useful in light of studies linking past participation in SNAP to unhealthy weight outcomes (e.g. Gibson, 2003, Zagorsky and Smith, 2009) and related concerns about the adequacy of pre-ARRA SNAP allotments for a healthy diet (Institute of Medicine, 2012). The ARRA expansions provide a unique opportunity to examine the change not only in food security and food expenditures but also on dietary intake and food consumption patterns that may follow an exogenous increase in SNAP benefits. 
This paper analyses the impact of the ARRA on diets of low-income individuals using 2007-2010 data from the National Health and Nutrition Examination Survey. Cross-sectional data on the diets of individuals in SNAP-eligible and SNAP-ineligible low-income households pre- and post ARRA allow us to estimate difference-in-difference models of the effects of SNAP changes in the ARRA. In addition to identifying the impact of the ARRA on the diets of millions of low-income Americans, our study also examines whether this effect varies across the dietary intake and quality distributions.

\section{Background}

Under federal rules, households with gross monthly incomes less than $130 \%$ of the federal poverty threshold (FPL) and net income under the FPL are eligible to receive SNAP benefits. The maximum SNAP allotment for eligible households is based on the Thrifty Food Plan (TFP), a guide for a low-cost meal plan that also aims to be nutritionally adequate. While the 2006 TFP does allow the purchase of some prepared foods, the market basket emphasizes home food production. SNAP benefits may not be used on ready-to-eat hot meals or in restaurants. In 2013, the average monthly SNAP benefit was approximately $\$ 275$ per household (USDA, 2014a).

Studies have suggested that the TFP may be insufficient for providing a nutritionally adequate diet and may assume that more time is spent in home food preparation than the data indicates (Rose, 2007; Mancino and Newman, 2007, Davis and You, 2010). Concerns have also been expressed that the TFP may be difficult to afford and implement in low-income food environments characterized by corner stores and smaller groceries (Neault et al., 2005). More

generally, studies report that healthy eating costs more (e.g. Townsend et al., 2009). Weighing in on the issue of SNAP allotment size, the Institute of Medicine has recommended that any 
assessment of the adequacy of the SNAP allotment should include the evaluation of the program's impact on food security and access to a healthy diet (Committee for the Examination of the Adequacy of Food Resources and SNAP Allotments, IOM, 2012).

The 2009 ARRA SNAP provisions (effective April 2009) provide a unique opportunity to assess how higher SNAP benefits may improve the food intake and diet quality of program participants. As part of the ARRA, SNAP benefits were increased by a constant dollar amount according to household size. This increase is equivalent to a $13.6 \%$ increase in the maximum allotment for that household size, with proportionally greater increases for families receiving less than the maximum allotment. Also, the 3 month time limits on program participation by jobless, working-age adults with no children was relaxed. In 2009, the average monthly SNAP benefit was $\$ 125$ per person, up nearly $22.6 \%$ from $\$ 102$ in 2008 (USDA, 2014b).

These ARRA expansions in SNAP were reported to increase the food security and food expenditures of program participants (Nord and Prell, 2011b). Specifically, between 2008 and 2009 , food insecurity was estimated to decrease by 2.2 percentage points from $25.03 \%$ in 2008 for low-income households (SNAP-eligible). Very low food security was estimated to decrease by 2 percentage points from $11.27 \%$ in $2008 .^{2}$ In addition, average food spending increased in these households by $2.2 \%$ as a result of the ARRA expansion in benefits. However, it is unclear whether the improved food security and increased food spending translate into improved diet quality.

Prior studies show that SNAP participation is consistently associated with increased expenditure on food (Fraker, 1990) but its association with diet quality or nutrient intake varies

\footnotetext{
${ }^{2}$ Food security status is based on responses to a series of questions in the Food Security Survey of the Current Population Survey that indicate whether households are having difficulty meeting basic food needs including being unable to afford balanced meals, cutting the size of meals because of too little money for food, or being hungry because of too little money for food. Food security status is determined by the number of food insecure conditions the household reports.
} 
across studies and types of nutrients (e.g. Butler and Raymond, 1996; Rose et al., 1998; Wilde et al., 1999; Gleason et al., 2000; Leung et al., 2012). A recent study by Castner and Mabil (2010) reports that higher food expenditures among SNAP participants are associated with an improved overall diet quality with higher fruit and vegetable intake though also with a lower whole grain intake and an increase in calories from SoFAAS (solid fats, alcohol and added sugars). While this suggests that increasing SNAP benefits may improve dietary intake of program participants, this study is cross-sectional and like most prior research on program effects, does not control for self-selection into SNAP. Little is known about the causal effect of SNAP benefit expansions under ARRA on food intake and diet quality of SNAP recipients.

More generally, epidemiological studies show that higher socioeconomic status (SES) is associated with better diet quality and lower dietary energy density (Kant and Graubard, 2007; Darmon and Drewnowski, 2008). Higher SES is linked to greater consumption of whole grains, lean meats, fish, fruits and vegetables while low-SES groups show higher consumption of fatty meats, refined grains, added fats, sugars and sweetened beverages (e.g. Cronin et al., 1982; La Vecchia et al., 1992; Shimakawa et al., 1994; van Rossum et al., 2000). Consistent with these socioeconomic differences in food types consumed, higher SES groups also have a greater intake of vitamins, minerals, and fiber than low-SES groups. Fat intake was also significantly associated with SES with more total fat and saturated fat intake among lower SES groups; however these differences were small in magnitude (Lopez-Azpiazu et al., 2003). SES is not significantly or consistently related to macronutrient intake including proteins, carbohydrates, or sucrose (Galobardes et al., 2001; Bolton-Smith et al., 1991). Similarly, the relationship between SES and total energy intake is not consistent (La Vecchia et al., 1992; Roos et al, 1996 ; Hulshof et al., 2003 ; van Rossum et al., 2000). Finally, a recent study of trends in overall dietary quality 
indicated that diet quality was consistently higher among high SES groups relative to low SES, and the quality gap widened over time from 1999-2000 to 2009-2010 (Wang et al., 2014). These associations of diet quality and SES suggest that the inome effects from the SNAP benefit expansions may result in improved diet quality for program recipients.

\section{Data}

We analyze data from the 2007-2008 and 2009-2010 National Health and Nutrition Examination Surveys (NHANES). The NHANES is an ongoing cross-sectional survey of the civilian non-institutionalized U.S. population which combines household interviews with standardized physical examinations. ${ }^{3}$ The survey examines a nationally-representative sample of individuals residing in counties across the country. It includes demographic, socioeconomic, dietary, and health-related questions designed to assess the health and nutritional status of adults and children in the United States, and a physical examination and testing component administered by trained medical personnel in a mobile examination center (MEC).

All NHANES respondents are eligible for two 24-hour dietary recall interviews. The first dietary recall interview is collected in-person in the MEC and the second interview is collected by telephone 3 to 10 days later. The dietary interview data contain information about each food eaten by a respondent during the previous 24-hour period (interview day of week, name and time of day of eating occasion, food code, food source, whether food was eaten at home or not, amount eaten in grams, and amounts of energy and 62 nutrients/food components) as well as daily aggregates of energy and nutrients/food components and information about water intake. For these latter data, USDA's Food and Nutrient Database for Dietary Studies (FNDDS) is used

\footnotetext{
${ }^{3}$ More information about the NHANES data is available at http://www.cdc.gov/nchs/nhanes.htm (accessed March 4, 2014). The unweighted response rates for NHANES interviews were $78 \%$ in $207-2008$ and $79 \%$ in $2009-2010$.
} 
to code individual foods and portion sizes reported by survey participants and to calculate nutrient intakes.

Dependent Variables: We analyze diet quality using the 2005 Healthy Eating Index (HEI2005) (Guenther et al., 2008). The HEI-2005 is a summary measure of overall diet quality with 12 components that compare reported dietary intake with recommendations in the 2005 Dietary Guidelines for America (USDA, 2007). We generate the index by applying publicly available algorithms to two days of NHANES' dietary recall data (USDA, 2012). Specifically, the dietary recall data are linked to the MyPyramid Equivalents Database (MPED) which calculates the dietary constituents of each food to facilitate comparisons with dietary guidance reflected in MyPyramid. ${ }^{4}$ Scores for the HEI-2005 and its components are then created by dividing the amount of each dietary constituent by total energy intake and comparing the ratio to standards that reflect the prevailing dietary guidance.

Of the 12 HEI-2005 components, 9 assess intake of total fruit; whole fruit; total vegetables; dark green vegetables, orange vegetables, and legumes; total grains; whole grains; milk; meats and beans; and oils. The 3 remaining components assess intake of saturated fats, sodium, and calories for solid fats, alcohol, and added sugars (SoFAAS), greater consumption of which is discouraged. ${ }^{5}$ HEI-2005 and component scores are calculated per 1000 calories to reflect the view that dietary recommendations should be met while maintaining energy balance (rather than by just eating large amounts of food).

In this study, we focus on overall HEI-2005 scores and the SoFAAS component of the HEI-2005 to measure diet quality. The score for the overall HEI-2005 ranges from 0 to 100 and

\footnotetext{
${ }^{4}$ For example, the MPED separates whole milk into the skim milk fraction and the solid fat fraction (see Guenther et al., 2008 and Reedy et al., 2010 for a full description of the calculation and application of the HEI-2005).

${ }^{5}$ Note that while SNAP dollars cannot be used to purchase alcohol, for those SNAP recipients whose food expenditures are greater than their SNAP benefit, an increase in SNAP benefit can free up out-of-pocket money previously spent on food items to be spent on other non-food or non-allowed items including alcohol.
} 
for the SoFAAS component, from 0 to 20, with higher scores indicating improved diets. Thus, a higher score on the overall HEI-2005 implies an improved overall diet quality, while higher scores on the SoFAAS component indicate a healthier diet with lower consumption of these discretionary calories. The HEI-2005 has been widely used in studies of diet quality (e.g. Beydoun et al. 2008, Mancino et al. 2009, Grimstvedt et al 2010, Todd et al 2010, Blake et al. 2011, Leung et al. 2012, Hanson and Olson 2013, and Gregory et al. 2013).

Note that the HEI was updated in 2010 to reflect revisions in federal dietary guidelines (USDHHS, 2010). While the revised HEI-2010 may be a better measure of dietary quality ${ }^{6}$, we use the HEI-2005 in our analysis because it reflects the dietary guidance available at the time of the ARRA. In addition to the HEI-2005, we analyze separate models for the effect of increased SNAP benefits on total daily energy intake, fruit and vegetable consumption ${ }^{7}$, and sugarsweetened beverages $(\mathrm{SSB})^{8}$. We also examine the intake of selected micronutrients (fiber, vitamins C \& D, sodium) and macronutrients (protein, carbohydrates, total fat and saturated fat). The Dietary Guidelines recommend increasing the intake of fiber and vitamin D while reducing intake of total fats, saturated fat, and sodium. We also analyze vitamin $\mathrm{C}$ intake as another indicator of fruit and vegetable consumption. Finally, while inadequate protein or carbohydrate intake is not an issue in American diets, we chose to include them in our analyses because of the increasing popularity of high-protein, and low-carbohydrate diets as weight-loss strategies.

Because our objective is to estimate the average (mean) treatment effect of SNAP on dietary intake, we follow prior analyses (Todd et al., 2010; USDA, 2012) and analyze intake

\footnotetext{
${ }^{6}$ Relative to the 2005 version, the HEI-2010 emphasizes more consumption of dark green vegetables and legumes and protein from plants and seafood over meat and poultry sources, while discouraging intake of refined grains and saturated fats.

${ }^{7}$ We calculate the total number of fruit and vegetable cup equivalents (excluding legumes) using the MPED database, but we exclude white potatoes from our analysis.

${ }^{8}$ This category includes soft drinks, carbonated; fruit drinks; non-fruit beverages (incl. energy drinks); nonalcoholic beers, wines, cocktails; beverage concentrates, dry not reconstituted; and presweetened iced tea from frozen concentrate or powdered mix. Beverages are also restricted to those with at least $50 \mathrm{kcal}$ per 8 ounces.
} 
using the average of two days of dietary recall data collected for each respondent. Although Tooze et al. (2010, p. 2858) argue that the average of two recalls is not the best way to estimate the distribution of dietary intake, they also argue that ..."the mean of the distribution of individual means provides an unbiased estimate of mean usual intake." Also, although an alternative to analyzing the average of two recalls would be to model the them separately with random individual intercepts, there is a possibility that the random intercepts might be correlated with observed covariates or that the distribution of the random intercepts may not be normal as assumed, which renders estimates from random effects models inconsistent (Wooldridge, 2010).

Sample Selection: According to federal rules, families with gross monthly incomes under $130 \%$ of the federal poverty threshold (FPL) are eligible to receive SNAP benefits if their net incomes are also under the FPL and they meet certain asset tests. ${ }^{9}$ In this study, we identify SNAP-eligible respondents as those with gross household income less than $150 \%$ of the federal poverty threshold for that household size. ${ }^{10}$ While this is higher than the federal criterion of $130 \%$ of the FPL, we adopt this higher threshold to account for possible imprecision in the household income data and also because of the argument that if the elasticity of labor supply is not zero, the sample of "eligible" persons should be larger than the sample who qualify for benefits (Ashenfelter, 1983; Newman, 2006). In addition, many states have adopted broad-based categorical eligibility rules to expand eligibility to households with incomes higher than $130 \%$ of

\footnotetext{
${ }^{9}$ Note that households with elderly or disabled members are not subject to gross income limits.

${ }^{10}$ Since the NHANES does not provide enough information to measure net income, or assets, we follow the literature (eg. Todd and Ver Ploeg, 2014; Kreider et al., 2012; Nord and Prell, 2011) and use the gross income criterion to define eligible households. Therefore, our classification of SNAP eligibility is subject to measurement error. However, such error is unlikely to be large. In 2010, $85 \%$ of all gross-income-eligible households were also eligible under net income criteria with even higher rates for households with children(Rosenbaum et al., 2013).
} 
the FPL. ${ }^{11}$ Finally, we also define SNAP eligibles to include those with incomes higher than the $150 \%$ threshold who report current receipt of SNAP benefits. ${ }^{12}$

Our sample includes SNAP-eligible NHANES respondents who had two days of dietary recall data recorded between the official start of the recession in October 2007 and December

2010. Since youth have access to food from school meal programs, we focus our analysis on those aged 18 and over, yielding a sample of 2,844 adult eligibles.

\section{Estimating Framework}

Analyses of the causal effects of SNAP on diet are complicated by the well-known problem that SNAP participants self-select into the program based on unobservable characteristics that may also be correlated with their diet quality. If, for example, SNAP participants are more (less) health-conscious than non-participants even in the absence of SNAP, simple estimates of the relationship between SNAP participation and diet quality would overestimate (underestimate) the causal relationship. The ARRA-changes to SNAP provide a "natural experiment" whereby pre-post ARRA changes in diet quality can be linked to an exogenous increase in SNAP benefits that, controlling for household size, is unrelated to any unobserved characteristics that may also alter diet quality. However, other changes between the pre- and post-ARRA periods could also impact diet quality independently of the stimulus. For example, food prices were extremely volatile during this period with large increases during the

\footnotetext{
${ }^{11}$ Note that starting in 2000, states have increasingly adopted broad-based categorical eligibility (BCE) rules to expand program access to households, often with gross incomes as high as $200 \%$ of the poverty threshold. We do not use these BCE rules to define SNAP eligibility because few of those rendered financially eligible under these relaxed gross income thresholds actually receive SNAP benefits because their net incomes are higher than the FPL. For example, the Congressional Budget Office estimated that on average, 1.8 million people annually would lose access to benefits if $\mathrm{BCE}$ was restricted (CBO, 2012), a small percentage of the 46 million receiving benefits in $2012 .$.

${ }^{12}$ SNAP data in the recent NHANES are collected at the household level. Information includes whether anyone in the household ever received SNAP benefits; benefit receipt in the past 12 months; and time since last received benefits within the past 12 months. We define SNAP recipients as those reporting benefit receipt during the 30 days prior to the interview in order to ensure that program participation information roughly corresponds to the period covered by the dietary recall interviews.
} 
early part of the recession, followed by a decline in 2009. From December 2008 to December 2009, the cost of the Thrifty Food Plan (TFP) declined by 3.5 to 4.0 percent and prices for a broader set of foods also declined. At the same time, prices for non-food items rose by $1.8 \%$ resulting in a large drop in the relative price of food (Nord and Prell, 2011b). To control for changes in these non-ARRA related factors, we could compare pre-post ARRA changes in the diet quality of SNAP participants to those of a control group of income-eligible non-participants using a standard difference-in-difference model. However, a potential complication to the above scenario necessitates a slightly different comparison.

Specifically, as detailed by Nord and Prell (2011b), the ARRA may induce changes in the composition of SNAP participants. This is because the increased benefits and relaxed eligibility rules for some may induce post-ARRA participation among those who may have been programeligible prior to the ARRA but chose not to participate because the time and other costs of applying were greater than the expected benefits of participation. In addition, the Great Recession has also created an influx of new SNAP participants due to under- or unemployment. These induced post-ARRA SNAP participants may be less food-needy and otherwise systematically different in their consumption patterns from pre-ARRA participants. In addition, those who stayed out of the program even when the benefits were increased may also be better off than those non-participants prior to the ARRA. These composition changes in SNAP participant and non-participant groups make it difficult to estimate effects of the benefit increase or even to gauge the direction of bias in any estimated effects.

Following the approach of Nord and Prell (2011b), we estimate difference-in-difference (DD) models comparing differences in pre-post ARRA diets for SNAP-eligible respondents (rather than participants) compared to those for ineligible respondents (rather than non- 
participants) with incomes just greater than $150 \%$ but less than $250 \%$ of the federal poverty threshold. This group has been used as a comparison for SNAP-eligibles in recent studies (eg. Todd and Ver Ploeg, 2014; Condon et al., 2015) and have been treated as "nearly SNAP-eligible households" by Nord and Prell (2011b) ${ }^{13}$ While respondents in this income range are likely to be more economically secure than those who are eligible, many are still considered low-income for public health insurance programs. For example, $250 \%$ FPL is used to define Medicaid and Children's Health Insurance Program eligibility in 13 states (Kenney and Pelletier, 2009) while another 11 states have higher limits of at least 300\% FPL for these programs. At the same time, respondents with incomes in the $150 \%-250 \%$ FPL range are unlikely to receive SNAP benefits even in states with broad-based categorical eligibility (see footnote 11). Since a large percentage of SNAP-eligible households do not participate in SNAP, the DD approach will underestimate the effect of the increase in benefits on SNAP participants but is a valid intent-to-treat effect.In equation (1) below,

$$
\mathrm{E}(\text { Diet Quality })=\mathrm{f}\left(\alpha+\beta \mathrm{X}_{i}+\gamma \mathrm{ARRA}_{i}+\delta \mathrm{ELIG}_{i}+\theta \mathrm{ARRA}^{*} \mathrm{ELIG}_{i}\right)
$$

Here ARRA is an indicator for dietary recall data collected from April 1, 2009 onward and ELIG identifies those who are eligible for SNAP. ${ }^{14}$ Assuming that changes in diet quality would be similar for both program eligibles and ineligibles in the absence of SNAP changes due to the ARRA (ie. parallel trends in the pre-ARRA period), the difference-in-difference, $\theta$, estimates the effect of the ARRA-related SNAP changes on average diet quality. Note that these estimates will incorporate changes in mean diet quality due to both higher SNAP benefits and

\footnotetext{
${ }^{13}$ Nord and Prell (2011b), in their analysis of the ARRA effects on food expenditures, define "nearly SNAP eligible households [ ] as those with incomes from 150 percent to 250 percent of the poverty line". Similarly, a recent study by Todd and Ver Ploeg (2014) on the utility of beverage restrictions on SNAP participants uses the $250 \%$ PIR threshold to define the low-income sample. Finally, a recent USDA study on the diet quality of Americans by SNAP participation status also used those with incomes between 130\% FPL and 300\% FPL as a comparison group for SNAP-eligibles (Condon et al., 2015).

${ }^{14}$ Dates of the dietary recall interviews and state identifiers are extracted from restricted data files in the NHANES.
} 
expanded participation in SNAP as a result of the ARRA. Our analysis also controls for respondent characteristics $\mathrm{X}_{\mathrm{i}}$ such as age, gender, education, employment status, and race/ethnicity, in addition to household-level covariates including the ratio of household income to the federal poverty threshold, household size, family structure (presence of a spouse or partner in the household), and fixed effects for calendar quarter. State dummies control for regional differences in food tastes and preferences that may be correlated with diet outcomes.

To further minimize the effect of compositional changes in SNAP participants, we also estimate the effects of SNAP expansion among those with a high school or lower education. If the less-educated group of low-income individuals faces a tighter food budget and is therefore more likely to enroll in SNAP even at the pre-ARRA benefit levels than those with higher education, the DD estimates for this group should more closely approximate the effect of higher SNAP benefits on dietary outcomes separate from any compositional changes due to expanded participation in the program.

We test the DD assumption of parallel trends by estimating a second model of diet quality and interacting quarter dummies with an indicator for SNAP eligibility. Specifically, we estimate the following:

$$
\mathrm{E}\left(\text { Diet Quality }_{i}\right)=\mathrm{f}\left(\mathrm{a}+\mathrm{bX} \mathrm{X}_{i}+\mathrm{c} \mathrm{ELIG}_{\mathrm{i}}+\sum^{13}{ }_{\mathrm{j}=2} \mathrm{~d}_{\mathrm{j}} \mathrm{Q}_{\mathrm{ji}}+\sum^{13}{ }_{\mathrm{j}=2} \mathrm{f}_{\mathrm{j}} \mathrm{Q}_{\mathrm{ij}} * \mathrm{ELIG}_{\mathrm{i}}\right)
$$

In equation (2), $\mathrm{Q}_{\mathrm{ji}}$ are 12 dummy variables indicating the quarter of the sample period from October 2007 to December 2010 in which the dietary recall data was recorded. The coefficients $d_{j}$ represents the change in dietary outcome by quarter while $f_{j}$ represents differences in this trajectory between SNAP-eligibles and near-eligibles. A joint test of these differences in the preARRA period, $\sum_{j=2}^{6} f_{j}=0$, will indicate the validity of the parallel trend assumption underlying the DD model. 
The statistical distributions of diet quality and intake can be quite skewed in some instances because a large number of people may have very low or zero intakes and a few may have high levels of intake. While OLS regressions are unbiased, tests of the hypotheses of interest can be considerably underpowered when the outcomes are substantially skewed. Therefore, we use Stata to estimate generalized linear models (GLM) based on gamma distributions which are known to accommodate a variety of skewed distribution shapes to obtain more efficient results. ${ }^{15}$

Our final sample including both SNAP eligible and near-eligibles consists of 4,158 NHANES respondents. All estimates are weighted using the 2-day dietary recall weight in the NHANES, thus making our estimates nationally representative, and standard errors reflect the complex design of the NHANES survey. In addition to GLM analyses of the conditional mean, we also estimate quantile regressions to minimize the effect of outliers and allow for heterogeneous responses to the ARRA at different points in the intake distribution.

\section{Results}

Table 1 presents characteristics of those over 18 years of age in SNAP-eligible and nearly-eligible households, in pre- and post-ARRA time periods. More than a third of those in SNAP-eligible households report participation in SNAP over the past 30 days and these rates increase from $34 \%$ pre-ARRA to $39 \%$ in the post-ARRA period. ${ }^{16}$ In spite of restricting the sample to those with incomes under $250 \%$ FPL, significant pre-ARRA differences in

15 Some sources (e.g. NCHS 2014) recommend a Box-Cox transformation to account for skewness in measures of diet quality. We instead account for skewness by using GLM models that have superior robustness properties (McCullagh and Nelder, 1989) and predictions after GLM models do not have issues of retransformation that are ubiquitous in Box-Cox models (Blough, Madden, and Hornbrook 1999; Manning, Basu and Mullahy 2005).

${ }^{16}$ Although also not reported, past-year SNAP participation in our sample is $43 \%$, consistent with other evidence that 30-day SNAP participation is underreported in the NHANES to a greater extent that past-year participation (Castner and Mabil, 2010). Note that our focus on eligible households sidesteps the issue of underreporting of SNAP participation. 
race/ethnicity, education and family structure remain between near-eligible and eligible respondents. Respondents in SNAP-eligible households are significantly less likely to be white compared to those in ineligible households; approximately 52\% of SNAP-eligible respondents are non-Hispanic black, Hispanic or from other races compared to $30 \%$ of those in near-eligible households. Compared to those who are ineligible for SNAP, pre-ARRA SNAP-eligible respondents appear significantly less likely to have education greater than high school $(27 \%$ versus $52 \%$ for near-eligibles), and significantly more likely to be single (52\% versus $41 \%$ ). Notably, the education profile of SNAP-eligible respondents indicates a more educated group post-ARRA compared to pre-ARRA - 40\% report college experience post-ARRA, a significantly higher rate than the $27 \%$ pre-ARRA. There are no other significant pre- versus post-ARRA differences in the composition of SNAP-eligible respondents.

Table 2a presents means of pre- and post-ARRA dietary intake and quality by SNAP eligibility status, while Table $2 \mathrm{~b}$ presents selected measures at different points in the sample distribution. There are few differences in dietary intake between SNAP-eligible and ineligible respondents. Average pre-ARRA daily energy intake is 1,990 calories for program eligible respondents, statistically similar to the 2,034 calorie intake reported by SNAP-ineligible respondents. ${ }^{17}$ Pre-ARRA saturated fat intake is significantly higher among SNAP-ineligible respondents but accounts for approximately $1 / 3$ of total fat intake for both program eligible and ineligibles, in line with the overall population (USDA \& USDHHS, 2010). Total fat intake is approximately $36 \%$ of total energy intake for both groups, on the high end of the $20-35 \%$ caloric share recommended in the dietary guidelines. ${ }^{18}$ Consistent with the findings in the US population

\footnotetext{
${ }^{17}$ Estimates of average energy requirements range from 1,600 to 2,400 calories per day for adult women and 2,000 to 3,000 calories per day for adult men, depending on age and physical activity level (USDA \& USDHHS, 2010).

${ }^{18}$ This calculation assumes there are 9 calories in a fat gram.
} 
overall, sodium intake for both groups is well above the upper limit of 2,300 $\mathrm{mg}$ a day in the dietary guidelines (USDA \& USDHHS, 2010).

Relative to those eligible for SNAP, fiber intake and consumption of fruit and vegetables is not significantly different from those who are SNAP-ineligible. Program eligibles consume 1.85 cups of fruit and vegetables pre-ARRA, a fifth cup less than those ineligible for the program, a statistically insignificant difference. At the same time, pre-ARRA SSB consumption for SNAP-eligible respondents is 178 calories per day, significantly higher than 131 calorie consumption of those ineligible for SNAP.

These mean intakes mask a large variation in consumption and dietary quality. As Table $2 \mathrm{~b}$ shows, a quarter of the overall sample reports consumption of over 218 SSB calories while a quarter of the sample records no SSB consumption and half of the sample reports fewer than 74 SSB calories consumed per day.Similarly, a quarter of the sample reports less than a cup of fruit and vegetable consumption while another quarter reports three times as much of such consumption.

Unsurprisingly, given the similarity of pre-ARRA dietary intake between SNAP-eligible and ineligible respondents, scores on the HEI 2005 show that on average, the pre-ARRA overall diet quality of eligible respondents is not significantly different from that for ineligibles (53.9 versus 54.9). Both groups achieve just over half of the maximum score for overall dietary quality indicating substantial room for improvement. Similarly, SoFAAS scores of 10.1 and 10.5 for SNAP eligible and near-eligibles respectively suggest that consumption of empty calories from solid fats and added sugars is well over the limit of $20 \%$ of energy intake associated with the maximum score of 20 for this component. ${ }^{19}$

\footnotetext{
${ }^{19}$ SoFAAS refers to the $12^{\text {th }}$ component of the HEI-2005.
} 
Tables 3, 4, and 5 report estimates from DD models of intake for the sample of individuals older than 18 years of age. Since micro- and macronutrient intake is likely to increase with higher calorie diets, we also estimate models that control for total energy intake to highlight changes in nutrient density or caloric share. We present these energy-adjusted estimates in the lower half of the tables indicating ARRA associations with the share of calories consumed in the different categories. Note that the HEI and SoFAAS component scores are already energyadjusted, therefore these latter models will indicate how diet quality varies with total energy intake.

Models adjusting for differences in socioeconomic and regional characteristics indicate that SNAP-eligibles prior to the ARRA are not significantly different in total energy intake from those ineligible for the program. Models controlling for total energy intake (in logarithms) reveal that pre-ARRA, SNAP-eligibles consume a significantly larger share of total calories from SSBs and also have lower intake of vitamin D, but are not different from ineligible respondents in overall diet quality, consumption of fruits and vegetables, and intake of other micro- and macronutrients examined in Tables 3 to 5. Perhaps reflecting the decline in food prices in 2009 (Nord and Prell, 2011b) and provisions of the ARRA, results from Tables 3 to 5 show that the post-ARRA period is associated with a significant increase in total energy intake. Controlling for this increase, the post-ARRA period is also linked to a higher relative intake of fiber, sodium, and fruits and vegetables, and a significant reduction in the share of calories from SSBs. ${ }^{20}$

DD estimates in Table 3 indicate that the ARRA-related SNAP changes (henceforth referred to as "SNAP expansions") have an insignificant effect on daily energy intake as well as consumption of fruits and vegetables (both in absolute amounts and as a share of total energy

\footnotetext{
${ }^{20}$ Among other results not presented here, overall diet quality has a significant, negative relationship with total energy intake. Similarly, the consumption of discretionary SoFAAS calories also increases with high calorie diets suggesting that such diets may generally be less healthy. A full set of results can be provided upon request.
} 
intake). Models that control for daily energy intake indicate a $17.4 \%$ increase in SSB calories associated with SNAP expansions though this effect falls short of standard levels of statistical significance $(\mathrm{p}=0.13) .{ }^{21} \mathrm{HEI}$ scores indicate that the SNAP expansion results in a significant $4 \%$ reduction in overall diet quality but no significant change in the HEI component related to the consumption of empty SoFAAS calories. Results from the test of the parallel trends assumption indicate that, given the pre-ARRA trends, a casual interpretation of DD estimates is valid for all the outcomes studied in Table 3.

Results in Tables 4 and 5 suggest that the SNAP expansion has no significant effect on the intake of fiber, sodium, vitamin C, carbohydrates, protein or total fat (both in absolute amounts and caloric shares), but resulted in a significant $5 \%$ increase in the share of calories from saturated fats. While the DD coefficients are positive and significant in models of vitamin D intake both in absolute levels and in share models (Table 4), the parallel-trends assumption is rejected in these models suggesting that the DD estimates may not indicate the effect of the SNAP expansions but may instead reflect pre-existing differences in vitamin D intake trends between SNAP eligibles and ineligibles prior to the passage of the SNAP changes.

The above results suggest that the SNAP expansion resulting from the ARRA had a negative effect on mean diet quality as measured by the HEI, but no other significant effects on mean intake of selected micro- and macronutrients and food types except for saturated fats. However, as the descriptive statistics in Table $2 \mathrm{~b}$ indicate, the intake and diet quality distributions are skewed so that effects measured at the mean may not accurately represent changes at the upper or lower ends of the intake distribution.

Table 6 presents quantile regression estimates of the effects of SNAP expansions on dietary intake and quality at the median, $25^{\text {th }}$, and $75^{\text {th }}$ percentiles of the intake distributions.

${ }^{21}$ The percentage change is calculated as $\exp (\beta)-1$. 
Results show a more nuanced portrait of changes across the intake distributions. Controlling for total energy intake and contrary to expectations, the SNAP expansion is associated with a significant decrease in fruit and vegetable consumption by approximately 0.2 cups at the $25^{\text {th }}$ percentile, equivalent to almost $22 \%$ decrease in at this level of consumption (relative to consumption at the $25^{\text {th }}$ percentile as reported in Table $2 \mathrm{~b}$ of 0.93 cups). At the same time, those reporting higher levels of fruit and vegetable intake in the upper half of the distribution appear to be unaffected by the SNAP expansion. Similarly, the decrease in mean diet quality reported in Table 3 appears to be driven by reductions among those with poor quality diets to begin with. Thus, the HEI scores are 4.4 points lower at the $25^{\text {th }}$ percentile (equivalent to approximately $10 \%$ decline relative to the $25^{\text {th }}$ percentile in Table $2 \mathrm{~b}$ ), and SoFAAS component scores are 1.4 points lower for those at the $25^{\text {th }}$ percentile (equivalent to a $25 \%$ reduction). These changes suggest that the SNAP benefit increases due to ARRA are associated with higher consumption of empty calories among those who are already consuming greater than recommended amounts of such food. Finally, controlling for total daily energy intake, the SNAP expansion is linked to significantly higher share of saturated fat intake for those at both ends of the intake distribution.

Compositional Changes: Recall that the DD estimates in Tables 3 to 6 indicate the combined change in diet quality or intake as a result of both the ARRA-related increase in SNAP benefits and potential post-ARRA changes in the composition of SNAP participants. As Table 2a indicates, the education profile of SNAP-eligible respondents shifted significantly in the postARRA period toward those with at least some college experience. To the extent that this moreeducated pool may be less food-needy or have other unobserved differences in their dietary 
habits compared to longer-term program participants, the estimates in Tables 3 to 5 may not represent the true effect of the SNAP expansions on pre-ARRA program participants.

Wee attempt to control for these compositional changes by examining the impact of SNAP expansions for those with high school or lower education who may be more likely to be longer-term SNAP participants. We estimate these effects by interacting the SNAP, ARRA, and ARRA*SNAP variables in (1) with two indicators for education level (high school and lower versus more than high school). Coefficients for the less educated group should more closely reflect the effect of higher SNAP benefits on dietary outcomes, separate from any compositional changes.

Table 7 presents estimates of the triple interaction between SNAP, ARRA, and the low education indicator. In addition, Table 7 also repeats the SNAP-ARRA interactions from Tables 3-5 for comparison. Results suggest that among those with a high school education or lower, the increased SNAP benefits due to the ARRA may significantly increase the share of total energy intake from SSBs by $46 \%$. While the full sample results indicate a significant $4 \%$ reduction in mean HEI-2005 scores, there are no significant changes in HEI for those with less education.

Table 8 presents estimates of the triple interaction between SNAP, ARRA, and the low education indicator from quantile regressions with and without controls for daily energy intake. Results link the SNAP expansions to significant 33.8 calorie increase in median SSB consumption (equivalent to almost a 50\% increase at the median SSB intake of 74 calories) and a 22 calorie increase in SSB intake at the $75^{\text {th }}$ percentile, but this change was not statistically significant. Controlling for daily energy intake, SNAP expansions are linked to significant increases in saturated fat consumption at either end of the intake distribution for the less educated. At the same time, higher benefits have no significant effects on the consumption of 
fruits and vegetables among the less educated sample. In contrast to the insignificant effects on mean dietary quality among the less educated in Table 7, Table 8 shows that, among this group, the SNAP benefit expansions are associated with a significant 4.03 point reduction in overall diet quality for those at the $25^{\text {th }}$ percentile of the diet quality distribute, a $9 \%$ decline (relative to the $25^{\text {th }}$ percentile of HEI as reported in Table $2 \mathrm{~b}$ ). For those with less education, Table 8 also shows a significant 1.9 point reduction in the $25^{\text {th }}$ percentile of the SoFAAS component of the HEI-2005, equivalent to a $34 \%$ reduction (relative to the $25^{\text {th }}$ percentile of SoFAAS scores in Table $2 b$ ). Thus, the SNAP benefit expansions appear to have reduced both overall diet quality and increasedconsumption of empty calories among those with low HEI and SoFAAS scores at the $25^{\text {th }}$ percentile (ie those already consuming poor quality diets). ${ }^{22}$

Regional Composition: A complication with the DD strategy presented above relates to the NHANES data collection schedule in which Mobile Examination Centers visit different regions of the country in different times of the year. Consequently, no dietary recall data is recorded from the Midwest region in the analysis period prior to the passage of the ARRA from October 2007 to the end of March 2009. We check the robustness of the GLM results to this preARRA regional exclusion by re-estimating models including only the northeast, west, and southern regions in the analysis. Results from this smaller sample of 3,415 cases are presented in Table 9 and indicate no substantive changes compared to results from the full sample. Analysis of caloric share for those over 18 years show similar, insignificant changes in most of the dietary outcomes associated with the ARRA as were presented for the full sample. These results give us

\footnotetext{
${ }^{22}$ Tables 7 and 8 are estimated using 4,151 respondents over 18 years with valid information on educational attainment. Results are similar when we restrict the sample to 2,669 cases with high school or lower educationexcept for smaller, less significant $21 \%$ increase $(\mathrm{p}<0.10)$ in mean SSB consumption, and a larger, more significant 46 calorie increase in SSB intake at the $75^{\text {th }}$ percentile (equivalent to $21 \%$ of the $75^{\text {th }}$ percentile intake).
} 
reasonable confidence that the DD estimates are not affected by the data collection schedule of the NHANES.

\section{Conclusion}

The 2009 ARRA increased SNAP benefits by an average of $17 \%$ per person and relaxed eligibility rules for participation in the SNAP program (Nord and Prell, 2011a). Recent studies have identified improvements in food security and increases in food expenditures among lowincome households due to these SNAP expansions in the ARRA (Nord and Prell, 2011b). In this study, we find that these increases may not translate into consistent improvements in nutrient intake and diet quality. Instead, the SNAP expansions from the ARRA may have simply encouraged pre-existing patterns of consumption, especially among those with poor dietary habits.

The ARRA-related SNAP expansions may affect dietary intake and quality via both higher SNAP benefits and expanded or induced participation in SNAP. To control for the compositional changes in SNAP participants, we focus on the effects of SNAP expansions among those who are less educated and potentially longer-term pre-ARRA program participants. Results suggest that the increased SNAP benefits increase the mean caloric share from SSBs and these changes are driven by those in the upper half of the SSB intake distribution. Among those with less education, higher SNAP benefits are related to lower overall diet quality and increased consumption of SoFAAS calories for those who already have a poor quality diet to begin with, with scores at the $25^{\text {th }}$ percentile of the diet quality distributions.

The apparent lack of improvement in dietary quality following the SNAP benefit increase is not surprising given that prior SNAP studies do not indicate consistent relationships between 
program participation and diet quality or nutrient intake (eg. Gleason et al., 2000). There are several explanations for our findings. First, among SNAP households that spend more on food than their monthly SNAP allotment, the higher benefits free money previously spent on basic food consumption for spending on discretionary food and other non-food items. This could result in increased consumption of undesirable foods with positive income elasticities such as SSBs or at least a less than dollar-for-dollar increase in food expenditures (eg., Fraker, 1990; Hoynes and Schanzenbach, 2009). Second, as Mancino and Guthrie (2014) point out, SNAP households are less likely to be aware of the Dietary Guidelines or the Food Pyramid recommendations for a healthy diet. Moreover, SNAP households tend to shop less frequently and are more interested in purchasing foods that keep well, implying a lower consumption of perishable items such as fresh fruits and vegetables. Third, studies suggest that low-income families spend less time in food preparation than the SNAP benefit calculation assumes (Rose 2007, Mancino and Newman, 2007). Higher SNAP benefits may enable these time-constrained recipients to trade money for time and purchase more costly convenience foods of lower quality.

Finally, note that our results only pertain to the specific increase in SNAP benefits contained in the ARRA, and should not be interpreted to mean that any increase in SNAP benefits will fail to yield healthier diets. Instead, the SNAP expansions undertaken by the ARRA may not have been large enough or focused enough to change pre-existing dietary habits. Results from the Healthy Incentives Pilot program aimed at reducing prices and increasing consumption of fruits and vegetables suggest that targeted increases in SNAP benefits may be more effective (Klerman et al., 2014). Higher food budgets, on their own, may not be sufficient to change dietary habits and may need to be combined with nutrition education and structural improvements in food environments to improve dietary outcomes. 
Our study results may also be affected by the lingering effects of induced SNAP participation in the post-ARRA period, even in the less educated sample. To the degree that these newer, induced enrollees are more or less health conscious, the effects of the SNAP changes may be over- or underestimated. ${ }^{23}$ Since a large percentage of SNAP-eligible households do not participate in the program, our study's focus on SNAP-eligibles also means that our results may understate the effect of SNAP expansions on program participants. Measurement error in dietary recall data may also reduce overall significance of our estimates. While the two days of 24-hour dietary recall data in the NHANES should reflect average intake patterns, the data may be susceptible to underreporting, especially for overweight or obese respondents (Archer et al., 2013; Black and Cole, 2001; Subar et al., 2003). Longitudinal data on program participation and dietary intake would enable more precise estimates of the effect of increasing SNAP benefits on dietary outcomes of program participants.

In spite of these caveats, this study provides useful information for efforts aimed at improving the health and nutrition of SNAP participants. By exploiting a natural experiment provided by the ARRA, we address well known problems of self-selection into the program and estimate causal effects of the changes in the SNAP program due to the ARRA. Overall, the results suggest that the ARRA-related increase in SNAP benefits did not improve overall diet quality or nutrient intake of recipients.

\footnotetext{
${ }^{23}$ To proxy for differences in health consciousness, we examined the number of fast food eating occasions in the past 7 days using data from the Flexible Consumer Behavior module of the NHANES. We found no significant differences betwee SNAP-eligible respondents, pre- and post-ARRA, suggesting that compositional changes due to the ARRA benefit expansion are less of an issue among the less educated SNAP eligibles. However, there may be other unobserved differences in health consciousness that we cannot fully account for.
} 


\section{REFERENCES}

Archer E, Hand GA, Blair SN. 2013. Validity of U.S. Nutritional Surveillance: National Health and Nutrition Examination Survey Caloric Energy Intake Data, 1971-2010. PLoS ONE 8(10): e76632. doi:10.1371/journal.pone.0076632

Beydoun, M, and YT. Wang. 2008. Do nutrition knowledge and beliefs modify the association of socio-economic factors and diet quality among US adults? Preventive Medicine, 46(2008):145-153.

Bhattacharya, Jayanta, Janet Currie, and Steven Haider. 2006. "Breakfast of Champions? The Nutritional Effects of the School Breakfast Program.” Journal of Human Resources 41(3):445-466.

Black AE, Cole TJ. 2001. Biased over- or under-reporting is characteristic of individuals whether over time or by different assessment methods. J Am Diet Assoc 101: 70-80.

Blake CE, Wethington E, Farrell TJ, Bisogni CA, Devine CM.2011. Behavioral contexts, food-choice coping strategies, and dietary quality of a multiethnic sample of employed parents. J Am Diet Assoc. 2011 Mar;111(3):401-7.

Blough, D.K., Madden, C.W., Hornbrook, M.C., 1999. Modeling risk using generalized linear models. Journal of Health Economics 18, 153-171.

Bolton-Smith C, SmithWC, Woodward M, Tunstall-Pedoe H. Nutrient intakes of different social-class groups: results from the Scottish Heart Health Study (SHHS). Br J Nutr $1991 ; 65: 321-35$.

Butler, J.S., Raymond, J.. 1996. The Effect of the Food Stamp Program on Nutrient Intake. Economic Inquiry, vol. 34, 1996, pp. 781-798. 
Castner, L. and Mabli, J. 2010. Food Expenditures and Diet Quality among Low-Income Households and Individuals.

Congressional Budget Office, Agricultural Reconciliation Act of 2012, CBO Cost

Estimate, April 23, 2012, Available at

http://www.cbo.gov/sites/default/files/cbofiles/attachments/HouseAgricultureReconciliation.pdf.

Condon, E, Susan D, Keri J, Carolyn L, James M, Emily M, and Katherine N. 2015. Diet Quality of Americans by SNAP Participation Status: Data from the National Health and Nutrition Examination Survey, 2007-2010. Prepared by Walter R. McDonald \& Associates, Inc. and Mathematica Policy Research for the Food and Nutrition Service.

Cronin FJ, Krebs-Smith SM, Wyse BW, Light L. Characterizing food usage by demographic variables. J Am Diet Assoc 1982;81:661-73.

Darmon N, Drewnowski A. 2008. Does Social Class Predict Diet Quality? American Journal of Clinical Nutrition, 2008; 87:1107-1117.

Davis, G. and W You. 2010. The Thrifty Food Plan is Not Thrifty When Labor Cost is Considered. Journal of Nutrition, 140: 854-857.

Devaney, Barbara, and Robert Moffitt. 1991. Dietary Effects of the Food Stamp Program. American Journal of Agricultural Economics, February 1991, pp. 202-211.

Food Resource Action Center. 2012. Supplemental Nutrition Assitance Program Number of Persons Participation, 5-Year Change. Available at http://frac.org/wpcontent/uploads/2011/01/snapdata2012 january.pdf

Fraker, T. 1990. "The Effects of Food Stamps on Food Consumption: A Review of the Literature.” Alexandria, VA: U.S. Department of Agriculture, Food and Nutrition Service, 1990. 
Frazao, E. 2009. Less-energy-dense diets of low-income women in California are associated with higher energy-adjusted costs but not with higher daily diet costs. Am J Clin Nutr September 2009; 90 (3): 701.

Galobardes B, Morabia A, Bernstein MS. Diet and socioeconomic position: does the use of different indicators matter? Int J Epidemiol 2001;30:334-40.

Gibson, D. 2003. "Food Stamp Program Participation Is Positively Related to Obesity in Low Income Women,” Journal of Nutrition 133:2225-31.

Gleason, P., A. Rangarajan, and C. Olson. 2000. Dietary Intake and Dietary Attitudes Among Food Stamp Participants and Other Low-Income Individuals. USDA, Food and Nutrition Service.

Gregory, Christian, Michelle Ver Pleog, Margaret Andrews, and Alisha Coleman-Jensen. Supplemental Nutrition Assistance (SNAP) Participation Leads to Models Changes in Diet Quality. U.S. Department of Agriculture, Economic Research Service, Economic Research Report Number 147, April 2013.

Grimstvedt, M , Woolf, K, Milliron, B and Manore, M. (2010). Lower Healthy Eating Index-2005 dietary quality scores in older women with rheumatoid arthritis v. healthy controls. Public Health Nutrition, 13, pp 1170-1177.

Guenther PM, Reedy J, Krebs-Smith SM. 2008. Development of the Healthy Eating Index -2005. J Am Diet Assoc. 2008, Nov;108(11):1896-901.

$\underline{\text { Guenther PM}}{ }^{1}$, Casavale KO, Reedy J, Kirkpatrick SI, Hiza HA, Kuczynski KJ, Kahle

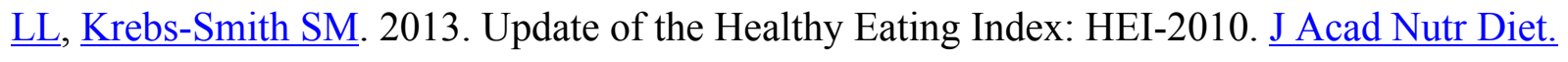
2013 Apr;113(4):569-80. 
Hanson, K and Olson, C. 2013. School Meals Participation and Weekday Dietary Quality Were Associated after Controlling for Weekend Eating among U.S. School Children Aged 6 to 17 Years. J. Nutr. 143: 714-721, 2013.

Hastings, J. and Washington, E. 2009. The First of the Month Effect: Consumer Behavior and Store Responses. NBER Working Paper, No. w14578.

Hausman, Jerry. 2001. "Mismeasured Variables in Econometric Analysis: Problems from the Right and Problems from the Left," The Journal of Economic Perspectives 15(4): 5767.

Hoynes, H. and Schanzenbach, D. 2009. Consumption Responses to In-Kind Transfers: Evidence from the Introduction of the Food Stamp Program. American Economic Journal: Applied Economics 2009, 1:4, 109-139.

Hoynes, H., McGranahan, L. \& Schanzenbach, D. 2014. SNAP and Food Consumption University of Kentucky Center for Poverty Research Discussion Paper Series, DP2014-03. Retrieved [Date] from http://www.ukcpr.org/Publications/DP2014-03.pdf.

Hulshof KF, Brussaard JH, Kruizinga AG, Telman J, Lowik MR. Socio-economic status, dietary intake and 10 y trends: the Dutch National Food Consumption Survey. Eur J Clin Nutr $2003 ; 57: 128-37$.

Institute of Medicine of the National Academies. 2012. Examination of the Adequacy of the Food Resources and SNAP Allotments. Available at http://www.iom.edu/Activities/Nutrition/SNAPadequacy/2012-JAN-17.aspx

Kant AK, Graubard BI. Secular trends in the association of socioeconomic position with self-reported dietary attributes and biomarkers in the US population: National Health and 
Nutrition Examination Survey (NHANES) 1971-1975 to NHANES 1999-2002. Public Health Nutr 2007;10:158-67.

Kennedy, E, Ohls J, Carlson S, Fleming K. 1995. The Healthy Eating Index - Design and Applications. Journal of the American Dietetic Association, 95(10):1103-1108.

Kenney, G. and Pelletier, J. 2009. Setting Income Thresholds in Medicaid and SCHIP:

Which Children Should be Eligible? Available at http://www.urban.org/UploadedPDF/411817_setting_income_thresholds.pdf

Klerman, J., Bertlett, S., Wilde, P., Ohlsho, L. 2014. The Short-Run Impact of the Healthy Incentives Pilot Program on Fruit and Vegetable Intake. American Journal of Agricultural Economics, May 2014, pp 1-10.

Kreider, B, Pepper, J., Gundersen, C. \& Jolliffe, D. 2012. Identifying the Effects of SNAP (Food Stamps) on Child Health Outcomes When Participation Is Endogenous and Misreported, Journal of the American Statistical Association, 107:499, 958-975

Kumcu, Mark and Phil Kaufman. 2011. Food Spending Adjustments During Recessionary Times. Amber Waves, September 2011. Economic Research Service: US Department of Agriculture.

La Vecchia C, Negri E, Franceschi S, Parazzini F, Decarli A. Differences in dietary intake with smoking, alcohol, and education. Nutr Cancer 1992;17:297-304.

Leung C, Ding E, Catalano P, Villamor E, Rimm E, Willet W. 2012. Dietary intake and Dietary Quality of Low-Income Adults in the Supplemental Nutrition Assistance Program. American Journal of Clinical Nutrition, 2012;96:977-988. 
Lipsky, L. 2009. Are energy-dense foods really cheaper? Reexamining the relation between food price and energy density. American Journal of Clinical Nutrition, 2009; 90:1397401.

Lopez-Azpiazu I, Sanchez-Villegas A, Johansson L, Petkeviciene J, Prattala R, MartinezGonzalez MA. Disparities in food habits in Europe: systematic review of educational and occupational differences in the intake of fat. J Hum Nutr Diet 2003;16:349-64.

Mancino, L, and Newman C. 2007. Who Has Time to Cook? How Family Resources Influence Food Preparation. USDA Economic Research Report Number 40, USDA Economic Research Service, May 2007.

Mancino L, Todd J, Linn BH. Separating what we eat from where:measuring the effect of food away from home on diet quality. Food Policy. 2009;34:557-62.

Manning, W. G., Basu, A., \& Mullahy, J. (2005). Generalized modeling approaches to risk adjustment of skewed outcomes data. Journal of Health Economics, 24(3), 465-488. Press.

McCullagh, P., \& Nelder, J. A. (1989). Generalized Linear Models, Second Edition. CRC

Neault N, Cook JT, Morris V, Frank DA. The Real Cost of a Healthy Diet: Healthful Foods Are Out of Reach for Low-Income Families in Boston, Massachusetts. Report published August 2005 by the Boston Medical Center Department of Pediatrics. Available at: http://dcc2.bumc.bu.edu/csnappublic/HealthyDiet_Aug2005.pdf

Nord, M, and Prell M. 2011a. Food Security of SNAP Recipients Improved Following the 2009 Stimulus Package. Amber Waves, Volume 9, Issue 2, June 2011: Economic Research Service, USDA. 
Nord, Mark, and Mark Prell. 2011b. Food Security Improved Following the 2009 ARRA Increase in SNAP Benefits, ERR-116, U.S. Department of Agriculture, Economic Research Service, April 2011.

Reedy, J, Krebs-Smith, S, Bosire, C. 2010. Evaluating the Food Environment Application of the Healthy Eating Index-2005. American Journal of Preventive Medicine, 38(5), May 2010:465-471.

Rose, D., Habicht, JP, Devaney, B. 1998. Household Participation in the Food Stamp and WIC Programs Increases the Nutrient Intakes of Preschool Children. Journal of Nutrition, 128 (3): 548-555.

Rosenbaum, D., Gonzales, S., Trisi, D. 2013. A Technical Assessment of SNAP and Medicaid Financial Eligibility under the Affordable Care Act (ACA). Center for Budget and Policy Priorities, March 2013. Available at http://www.cbpp.org/sites/default/files/atoms/files/321-13health.pdf

Roos E, Prattala R, Lahelma E, Kleemola P, Pietinen P. Modern and healthy?: socioeconomic differences in the quality of diet. Eur J Clin Nutr 1996;50:753-60.

Rose, Donald. 2007. Food Stamps, The Thrifty Food Plan, and Meal Preparation: The Importance of the Time Dimension for US Nutrition Policy. J Nutr Educ Behav.39:226-232.

Shapiro, J., 2005. "Is there a Daily Discount Rate? Evidence from the Food Stamp Nutrition Cycle.” Journal of Public Economics 89(2-3): 303-325, February.

Shimakawa T, Sorlie P, Carpenter MA, et al. 1994. Dietary intake patterns and sociodemographic factors in the atherosclerosis risk in communities study. ARIC Study Investigators. Prev Med 1994;23:769-80. 
Subar AF, Kipnis V, Troiano RP, Midthune D, Schoeller DA, et al. 2003. Using intake biomarkers to evaluate the extent of dietary misreporting in a large sample of adults: the OPEN study. Am J Epidemiol 158: 1-13.

Todd, J.E., Ver Ploeg, M. 2014. Caloric beverage intake among adult supplemental nutrition assistance program participants. American Journal of Public Health 104(9): e80-e85.

Todd, Jessica E., Lisa Mancino, and Biing-Hwan Lin. 2010. The Impact of Food Away From Home on Adult Diet Quality, ERR-90, U.S. Department of Agriculture, Economic Research Service, February 2010.

Tooze, J. A., Kipnis, V., Buckman, D. W., Carroll, R. J., Freedman, L. S., Guenther, P. M., Krebs-Smith, S. M., Subar, A. F. and Dodd, K. W. (2010), A mixed-effects model approach for estimating the distribution of usual intake of nutrients: The NCI method. Statist. Med., 29: 2857-2868. doi: 10.1002/sim.4063

Townsend MS, Aaron GJ, Monsivais P, Keim NL, Drewnowski A. Less-energy-dense diets of low-income women in California are associated with higher energy-adjusted diet costs. Am J Clin Nutr 2009;89:1220-6.

USDA, Center for Nutrition Policy and Promotion. 2006. Healthy Eating Index - 2005 CNPP Fact Sheet No. 1, December 2006.

USDA, Center for Nutrition Policy and Promotion. 2012. Healthy Eating Index - 2005 Development and Evaluation Technical Report Support Files. Available at http://www.cnpp.usda.gov/HealthyEatingIndex-2005report.htm

USDA, Economic Research Service. 2012. Food Consumption and Nutrient Intakes. Available at http://www.ers.usda.gov/data-products/food-consumption-and-nutrientintakes.aspx\#26671 
USDA, Food and Nutrition Service. 2014a. Supplemental Nutrition Assistance Program Average Monthly Benefit Per Household. Available at http://www.fns.usda.gov/pd/19SNAPavg\$HH.htm

USDA, Food and Nutrition Service. 2014b. Supplemental Nutrition Assistance Program Participation and Costs. Available at http://www.fns.usda.gov/pd/snapsummary.htm

U.S. Department of Agriculture and U.S. Department of Health and Human Services. Dietary Guidelines for Americans, 2010. $7^{\text {th }}$ Edition, Washington, DC: U.S. Government Printing Office, December 2010.

US Department of Health and Human Services and USDA. 2005. Dietary Guidelines for Americans, 2005. Available at http://www.healtierus.gov/dietaryguidelines

U.S. National Cancer Institute (NCI)> 2014. Healthy Eating Index: HEI Tools for Researchers. Available from: http://appliedresearch.cancer.gov/hei/tools.html\#intake. Accessed October 1, 2014.

U.S. National Center for Health Statistics (NCHS). 2014. "Evaluating the Effects of Covariates on Usual Dietary Intake.” Available from:

http://www.cdc.gov/nchs/tutorials/dietary/advanced/EvaluateCovariates/index.htm. Accessed October 1, 2014.

Van Rossum CT, van de MH, Witteman JC, Grobbee E, Mackenbach JP. Education and nutrient intake in Dutch elderly people. The Rotterdam Study. Eur J Clin Nutr 2000;54:159-65.

Ver Ploeg, M., and Ralston, K. 2008. Food Stamps and Obesity: What Do we Know? Economic Information Bulletin, 34, March 2008: US Department of Agriculture, Economic Research Service. 
Wang DD, Leung CW, Li Y, Ding EL, Chiuve SE, Hu FB, Willett WC. 2014. Trends in dietary quality among adults in the United States, 1999 through 2010. JAMA Intern Medicine, 2014, October 1: 174(10): 1587-95.

Wilde, P., P.E. McNamara, and C.K. Ranney. 1999. “The Effects of Income and Food Programs on Dietary Quality: a Seemingly Unrelated Regression Analysis with Error Components,” American Journal of Agricultural Economics, 81:201-213.

Wilde, P. and Ranney, C. 2000. The monthly food stamp cycle: Shopping frequency and food intake decisions in an endogenous switching regression framework. American Journal of Agricultural Economics, 82(1):200-213, February 2000.

Wooldridge, Jeffrey. 2010. Econometric Analysis of Cross Section and Panel Data. The MIT Press. Cambridge, MA.

Zagorsky, J. and Smith, P. 2009. Does the U.S. Food Stamp Program Contribute to Adult Weight Gain? Economics and Human Biology, 2009, 7(2):246-258. 
Table 1: Mean Characteristics by SNAP Eligibility $(\mathrm{n}=4158)$

\begin{tabular}{|c|c|c|c|c|}
\hline \multirow[t]{2}{*}{ Variable } & \multicolumn{2}{|c|}{$\begin{array}{l}\text { SNAP Eligible } \\
\left(\text { Income }<=150 \% \mathrm{FPL}^{\mathrm{a}} \text { ) }\right.\end{array}$} & \multicolumn{2}{|c|}{$\begin{array}{l}\text { Ineligible for SNAP } \\
(150-250 \% \text { FPL })\end{array}$} \\
\hline & Pre-ARRA & Post-ARRA & Pre-ARRA & Post-ARRA \\
\hline Past 30-day SNAP & $34 \%$ & $39 \%$ & $\overline{0}$ & 0 \\
\hline Male & $42 \%$ & $44 \%$ & $46 \%$ & $45 \%$ \\
\hline Age & & & & \\
\hline Age $19-24$ years & $20 \%$ & $20 \%$ & $12 \%$ & $10 \%$ \\
\hline Age $25-34$ years & $20 \%$ & $22 \%$ & $19 \%$ & $18 \%$ \\
\hline Age $35-44$ years & $19 \%$ & $19 \%$ & $17 \%$ & $20 \%$ \\
\hline Age $45-54$ years & $17 \%$ & $16 \%$ & $15 \%$ & $15 \%$ \\
\hline Age 55-64 years & $11 \%$ & $10 \%$ & $12 \%$ & $12 \%$ \\
\hline $\begin{array}{l}\text { Age } 65 \text { years and older } \\
\text { Race/Ethnicity }\end{array}$ & $15 \%{ }^{++}$ & $13 \%$ & $25 \%{ }^{++}$ & $26 \%$ \\
\hline White & $48 \%^{+}$ & $51 \%$ & $70 \%^{+}$ & $66 \%$ \\
\hline Non-Hispanic Black & $15 \%$ & $20 \%$ & $9 \%$ & $13 \%$ \\
\hline Hispanic & $32 \%$ & $23 \%$ & $17 \%$ & $13 \%$ \\
\hline Other Race & $5 \%$ & $7 \%$ & $4 \%$ & $7 \%$ \\
\hline Education & & & & \\
\hline Less than High School/GED & $46 \% *$ & $35 \% *$ & $22 \%$ & $19 \%$ \\
\hline High School/GED & $27 \%$ & $25 \%$ & $26 \%$ & $29 \%$ \\
\hline Some College & $21 \% *^{*+}$ & $28 \% *$ & $38 \%{ }^{++}$ & $31 \%$ \\
\hline College Graduate & $6 \%{ }^{*+++}$ & $12 \% *$ & $14 \% *^{+++}$ & $21 \% *$ \\
\hline Missing Education & $0.04 \%$ & $0.4 \%$ & $0.4 \%$ & $0.2 \%$ \\
\hline$\frac{\text { Employed }}{\text { Marital Status }}$ & $43 \%$ & $45 \%$ & $59 \%$ & $59 \%$ \\
\hline Single & $52 \%^{+}$ & $50 \%$ & $41 \%^{+}$ & $39 \%$ \\
\hline With Spouse/Partner & $46 \%$ & $48 \%$ & $57 \%$ & $59 \%$ \\
\hline Missing Marital Status & $3 \%$ & $2.5 \%$ & $1 \%$ & $1.5 \%$ \\
\hline Family Size & 3.2 & 3.1 & 2.7 & 2.8 \\
\hline Income/FPL & $0.92^{+++}$ & 0.92 & $2.01^{+++}$ & 2.01 \\
\hline $\mathrm{n}$ & \multicolumn{2}{|c|}{2844} & \multicolumn{2}{|c|}{1314} \\
\hline
\end{tabular}

Weighted means. Sample comprised of respondents over 18 year with two days of dietary recall data recorded between October 2007 and December 2010 and household incomes $<250 \%$ FPL. The symbols $* * *(p<0.01), * *(p<0.05)$, and $*(p<0.10)$ indicate the significance level of the difference, conditional on SNAP eligibility, between pre- and post-ARRA periods (based on a two-tailed t-test). The symbols $+(\mathrm{p}<0.10),++(\mathrm{p}<0.05),+++(\mathrm{p}<0.01)$ indicate significance level of pre-ARRA differences between SNAP eligible and ineligibles.

${ }^{a}$ FPL $=$ Federal Poverty Threshold

Source: NHANES 2007-2010. 
Table 2a: Mean Daily Consumption by SNAP Eligibility $(\mathrm{n}=4158)$

\begin{tabular}{|c|c|c|c|c|}
\hline \multirow[t]{2}{*}{ Outcomes } & \multicolumn{2}{|c|}{$\begin{array}{l}\text { SNAP Eligible } \\
\left(\text { Income }<=150 \% \mathrm{FPL}^{\mathrm{a}} \text { ) }\right.\end{array}$} & \multicolumn{2}{|c|}{$\begin{array}{l}\text { Ineligible for SNAP } \\
(150-250 \% \text { FPL })\end{array}$} \\
\hline & Pre-ARRA & $\begin{array}{l}\text { Post- } \\
\text { ARRA }\end{array}$ & Pre-ARRA & Post-ARRA \\
\hline Total Energy (calories) & 1990 & 2050 & 2034 & 2072 \\
\hline Fat (\% energy) & $36 \%$ & $36 \%$ & $36 \%$ & $36 \%$ \\
\hline Saturated Fat ( $\%$ energy) & $11 \%^{+}$ & $11 \%$ & $12 \%{ }^{+}$ & $11 \%$ \\
\hline Sodium (mg) & 3213 & 3402 & 3310 & 3474 \\
\hline Protein (\% energy) & $16 \%$ & $16 \%$ & $16 \%$ & $16 \%$ \\
\hline Carbohydrates ( $\%$ energy) & $51 \%$ & $51 \%$ & $50 \%$ & $50 \%$ \\
\hline Fiber (gms) & 14.7 & 15.5 & 15.5 & 16.8 \\
\hline Vitamin C (gms) & 78.5 & 84.5 & 81.1 & 82.5 \\
\hline Vitamin D (mcg) & $4.1^{* *}$ & $4.9^{* *}$ & 4.8 & 4.9 \\
\hline SSB calories & $178^{++}$ & 164 & $131^{++}$ & 105 \\
\hline Fruit \& Vegetable cups & 1.85 & 2.07 & 2.05 & 2.33 \\
\hline BMI & 29.3 & 29.5 & 28.6 & 28.7 \\
\hline Overall HEI-2005 & 53.9 & 53.5 & 54.9 & 56.6 \\
\hline SoFAAS (HEI-12) & 10.1 & 10.3 & 10.5 & 11.3 \\
\hline
\end{tabular}

Weighted means. Sample comprised of respondents over 18 years with two days of dietary recall data recorded between October 2007 and December 2010 and household incomes under 250\% of FPL. SSB stands for sugarsweetened beverages. HEI-2005 stands for the 2005 Healthy Eating Index. SoFAAS stands for solid fats, alcohol and added sugars.

The symbol ** $(\mathrm{p}<0.05)$ indicates the significance level of the difference, conditional on SNAP eligibility, between pre- and post-ARRA periods (based on a two-tailed t-test). The symbol $++(p<0.05)$ indicates the significance level of the pre-ARRA difference between SNAP eligibles and ineligibles based on a two-tailed t-test.

${ }^{a}$ FPL $=$ Federal Poverty Threshold

Source: NHANES 2007-2010

Table 2b: Intake and Diet Quality Percentiles $(\mathrm{n}=4,158)$

\begin{tabular}{|l|l|l|l|}
\hline & $25^{\text {th }}$ Percentile & $50^{\text {th }}$ Percentile & $75^{\text {th }}$ Percentile \\
\hline Total calories & 1442 & 1891 & 2425 \\
\hline SSB calories & 0 & 74 & 214 \\
\hline Fruit-veg cups & 0.93 & 1.72 & 2.75 \\
\hline HEI-2005 & 44.61 & 54.19 & 64.19 \\
\hline SoFAAS & 5.56 & 10.57 & 15.50 \\
\hline
\end{tabular}

Weighted percentiles. SSB stands for sugar- sweetened beverages. SoFAAS stands for solid fats, alcohol and added sugars. 
Source: NHANES 2007-2010 
Table 3: DD Estimates of Changes in Food Intake and Diet Quality $(\mathrm{n}=4,158)$

\begin{tabular}{l|l|l|l|l|l}
\hline & $\begin{array}{l}\text { Total } \\
\text { Energy }\end{array}$ & $\begin{array}{l}\text { SSB } \\
\text { Calories }\end{array}$ & $\begin{array}{l}\text { Fruit-Veg } \\
\text { Cups }\end{array}$ & $\begin{array}{l}\text { HEI } \\
2005\end{array}$ & SoFAAS \\
\hline ARRA & $0.12^{* * *}$ & $-0.50^{* *}$ & $0.31^{* *}$ & 0.04 & 0.07 \\
& $(0.03)$ & $(0.25)$ & $(0.15)$ & $(0.04)$ & $(0.12)$ \\
SNAP-ELIG & -0.02 & 0.21 & -0.03 & 0.006 & -0.04 \\
& $(0.03)$ & $(0.14)$ & $(0.06)$ & $(0.02)$ & $(0.07)$ \\
SNAP- & -0.02 & 0.11 & -0.07 & $-0.04^{* *}$ & -0.06 \\
ELIG*ARRA & $(0.03)$ & $(0.12)$ & $(0.06)$ & $(0.02)$ & $(0.06)$ \\
$\begin{array}{l}\text { Parallel Trends } \\
\text { (p-value) }\end{array}$ & 0.51 & 0.79 & 0.18 & 0.96 & 0.35 \\
\hline
\end{tabular}

Controlling for Total Energy Intake

\begin{tabular}{l|l|l|l|l|l}
\hline ARRA & - & - & $0.30^{* *}$ & 0.05 & 0.10 \\
& & $0.59^{* * *}$ & $(0.15)$ & $(0.04)$ & $(0.13)$ \\
SNAP-ELIG & - & $0.22)$ & & & \\
& & $\left(0.27^{* *}\right.$ & 0.0005 & 0.006 & -0.03 \\
SNAP- & - & $0.06)$ & $(0.02)$ & $(0.06)$ \\
$\begin{array}{l}\text { ELIG*ARRA } \\
\text { Parallel Trends } \\
\text { (p-value) }\end{array}$ & - & $(0.10)$ & $0.08(0.06)$ & $-0.04 * *$ & -0.06 \\
\hline
\end{tabular}

$* * * \mathrm{p}<0.01 ; * * \mathrm{p}<0.05 ; * \mathrm{p}<0.10$

Standard errors are in parentheses.

Models also control for age, gender, education (high school/ged; some college; college grad;

missing education), employment status, race/ethnicity, the ratio of household income to federal poverty threshold, household size, family structure (divorced/separated/widowed/never married, missing marital status), quarterly time trend, and state fixed effects. SSB stands for sugarsweetened beverages. SoFAAS stands for solid fats, alcohol and added sugars. HEI-2005 stands for 2005 Healthy Eating Index. The percentage change is calculated as $\exp (\beta)-1$.

Source: NHANES 2007-2010 
Table 4: DD Estimates of Changes in Selected Micronutrient Intake $(\mathrm{n}=4,158)$

\begin{tabular}{l|l|l|l|l|l}
\hline & $\begin{array}{l}\text { Total } \\
\text { Calories }\end{array}$ & $\begin{array}{l}\text { Fiber } \\
(\mathrm{gms})\end{array}$ & $\begin{array}{l}\text { Sodium } \\
(\mathrm{mg})\end{array}$ & $\begin{array}{l}\text { Vitamin C } \\
(\mathrm{mg})\end{array}$ & $\begin{array}{l}\text { Vitamin D } \\
(\mathrm{mcg})\end{array}$ \\
\hline ARRA & $0.12^{* * *}$ & $0.28^{* * *}$ & $0.18^{* * *}$ & 0.16 & 0.15 \\
$(0.03)$ & $(0.09)$ & $(0.03)$ & $(0.13)$ & $(0.18)$ \\
\hline SNAP-ELIG & -0.02 & -0.03 & 0.004 & -0.03 & $-0.19^{* *}$ \\
& $(0.03)$ & $(0.04)$ & $(0.03)$ & $(0.07)$ & $(0.08)$ \\
\hline SNAP-ELIG*ARRA & -0.02 & -0.05 & -0.03 & 0.02 & $0.16^{*}$ \\
& $(0.03)$ & $(0.05)$ & $(0.04)$ & $(0.08)$ & $0.09)$ \\
$\begin{array}{l}\text { Parallel Trends } \\
\text { (p-value) }\end{array}$ & 0.51 & 0.15 & 0.70 & 0.97 & 0.09 \\
\hline
\end{tabular}

Controlling for Total Energy Intake

\begin{tabular}{l|l|l|l|l|l}
\hline ARRA & - & $\begin{array}{l}0.21^{* *} \\
(0.09)\end{array}$ & $\begin{array}{l}0.09^{* * *} \\
(0.03)\end{array}$ & $\begin{array}{l}0.19 \\
(0.14)\end{array}$ & $\begin{array}{l}-0.03 \\
(0.17)\end{array}$ \\
\hline SNAP-ELIG & - & -0.02 & 0.02 & -0.04 & $-0.20^{* *}$ \\
& & $(0.04)$ & $(0.02)$ & $(0.07)$ & $0.08)$ \\
\hline SNAP-ELIG*ARRA & - & -0.04 & -0.004 & 0.03 & $0.19^{* *}$ \\
& $(0.05)$ & $(0.03)$ & $(0.07)$ & $0.08)$ \\
$\begin{array}{l}\text { Parallel Trends } \\
\text { (p-value) }\end{array}$ & - & 0.29 & 0.75 & 0.73 & 0.03 \\
\hline
\end{tabular}

Standard errors are in parentheses.

$* * * \mathrm{p}<0.01 ; * * \mathrm{p}<0.05 ;{ }^{*} \mathrm{p}<0.10$

Models also control for age, gender, education (high school/ged; some college; college grad; missing education), employment status, race/ethnicity, the ratio of household income to federal poverty threshold, household size, family structure (divorced/separated/widowed/never married, missing marital status), quarterly time trend, and state fixed effects.

The percentage change is calculated as $\exp (\beta)-1$.

Source: NHANES 2007-2010 
Table 5: DD Estimates of Changes in Selected Macronutrient Intake $(n=4,158)$

\begin{tabular}{l|l|l|l|l|l}
\hline & $\begin{array}{l}\text { Total } \\
\text { Calories }\end{array}$ & $\begin{array}{l}\text { Protein } \\
(\mathrm{gms})\end{array}$ & $\begin{array}{l}\text { Carb } \\
(\mathrm{gms})\end{array}$ & $\begin{array}{l}\text { Total fats } \\
(\mathrm{gms})\end{array}$ & $\begin{array}{l}\text { Saturated Fats } \\
(\mathrm{gms})\end{array}$ \\
\hline ARRA & $\begin{array}{l}0.12^{* * *} \\
(0.03)\end{array}$ & $\begin{array}{l}0.10^{* * *} \\
(0.03)\end{array}$ & $\begin{array}{l}0.12^{* * *} \\
(0.04)\end{array}$ & $\begin{array}{l}0.11^{* *} \\
(0.05)\end{array}$ & $\begin{array}{l}0.15^{* *} \\
(0.07)\end{array}$ \\
\hline SNAP-ELIG & $\begin{array}{l}-0.02 \\
(0.03)\end{array}$ & $\begin{array}{l}-0.04 \\
(0.03)\end{array}$ & $\begin{array}{l}0.001 \\
(0.04)\end{array}$ & $\begin{array}{l}-0.04 \\
(0.04)\end{array}$ & $\begin{array}{l}-0.08 \\
(0.05)\end{array}$ \\
\hline SNAP-ELIG*ARRA & -0.02 & -0.002 & -0.01 & -0.03 & 0.02 \\
$(0.03)$ & $(0.03)$ & $(0.03)$ & $(0.04)$ & $(0.05)$ \\
$\begin{array}{l}\text { Parallel Trends } \\
\text { (p-value) }\end{array}$ & 0.51 & 0.91 & 0.42 & 0.35 & 0.50 \\
\hline
\end{tabular}

Controlling for Total Energy Intake

\begin{tabular}{l|ll|l|l|l}
\hline ARRA & - & -0.005 & 0.02 & -0.02 & -0.02 \\
& $(0.03)$ & $(0.02)$ & $(0.03)$ & $(0.05)$ \\
\hline SNAP-ELIG & - & -0.02 & 0.02 & -0.01 & -0.04 \\
& $(0.03)$ & $(0.02)$ & $(0.02)$ & $(0.03)$ \\
\hline SNAP-ELIG*ARRA & - & 0.01 & 0.005 & -0.01 & $0.05^{*}$ \\
& $(0.02)$ & $(0.02)$ & $(0.02)$ & $(0.03)$ \\
$\begin{array}{l}\text { Parallel Trends } \\
\text { (p-value) }\end{array}$ & - & 0.74 & 0.86 & 0.84 & 0.55 \\
\hline
\end{tabular}

Standard errors are in parentheses.

$* * * \mathrm{p}<0.01 ; * * \mathrm{p}<0.05 ;{ }^{*} \mathrm{p}<0.10$

Models also control for age, gender, education (high school/ged; some college; college grad; missing education), employment status, race/ethnicity, the ratio of household income to federal poverty threshold, household size, family structure (divorced/separated/widowed/never married, missing marital status), quarterly time trend, and state fixed effects.

The percentage change is calculated as $\exp (\beta)-1$.

Source: NHANES 2007-2010 
Table 6: DD Estimates from Quantile Regressions ( $\left.\mathrm{n}=4,158^{1}\right)$

\begin{tabular}{|c|c|c|c|c|c|c|c|}
\hline & $\begin{array}{l}\text { Total } \\
\text { Daily } \\
\text { Kcal }\end{array}$ & $\begin{array}{l}\text { SSB } \\
\text { Calories }\end{array}$ & $\begin{array}{l}\text { Fruit-Veg } \\
\text { Cups }\end{array}$ & $\begin{array}{l}\text { Saturated } \\
\text { Fat (gms) }\end{array}$ & $\begin{array}{l}\text { Sodium } \\
(\mathrm{mg})\end{array}$ & $\begin{array}{l}\text { HEI } \\
2005\end{array}$ & SoFAAS \\
\hline $25^{\text {th }}$ pctile & $\begin{array}{l}-16.45 \\
(48.15)\end{array}$ & $\begin{array}{l}0.00 \\
(3.51)\end{array}$ & $\begin{array}{l}-0.23 * * * \\
(0.08)\end{array}$ & $\begin{array}{l}-1.36^{*} \\
(0.80)\end{array}$ & $\begin{array}{l}-68.68 \\
(97.41)\end{array}$ & $\begin{array}{l}-4.12 * * * \\
(1.00)\end{array}$ & $\begin{array}{l}-1.30^{* *} \\
(0.61)\end{array}$ \\
\hline Median & $\begin{array}{l}32.21 \\
(52.65)\end{array}$ & \begin{tabular}{|l|}
3.06 \\
$(9.13)$
\end{tabular} & $\begin{array}{l}-0.30^{* * *} \\
(0.12)\end{array}$ & $\begin{array}{l}0.38 \\
(0.95)\end{array}$ & $\begin{array}{l}119.39 \\
(95.99)\end{array}$ & $\begin{array}{l}-1.17 \\
(1.11)\end{array}$ & $\begin{array}{l}-0.59 \\
(0.55)\end{array}$ \\
\hline $75^{\text {th }}$ pctile & $\begin{array}{l}-32.77 \\
(62.26)\end{array}$ & $\begin{array}{l}-19.03 \\
(19.0)\end{array}$ & $\begin{array}{l}-0.18 \\
(0.14)\end{array}$ & $\begin{array}{l}3.51 * * * \\
(1.27)\end{array}$ & $\begin{array}{l}-204.23 \\
(140.10)\end{array}$ & $\begin{array}{l}-1.29 \\
(1.08)\end{array}$ & $\begin{array}{l}0.005 \\
(0.58)\end{array}$ \\
\hline \multicolumn{8}{|c|}{ Controlling for Total Energy Intake } \\
\hline $25^{\text {th }}$ pctile & - & \begin{tabular}{|l|}
1.47 \\
$(3.51)$
\end{tabular} & $\begin{array}{l}-0.20 * * \\
(0.09)\end{array}$ & $\begin{array}{l}1.52^{* * *} \\
(0.56)\end{array}$ & $\begin{array}{l}-74.88 \\
(54.29)\end{array}$ & $\begin{array}{l}-4.43 * * * \\
(1.01)\end{array}$ & $\begin{array}{l}-1.40^{* *} \\
(0.55)\end{array}$ \\
\hline Median & - & $\begin{array}{l}7.06 \\
(9.44)\end{array}$ & $\begin{array}{l}-0.03 \\
(0.11)\end{array}$ & $\begin{array}{l}0.86 \\
(0.57)\end{array}$ & $\begin{array}{l}29.62 \\
(63.05)\end{array}$ & $\begin{array}{l}-0.89 \\
(1.10)\end{array}$ & $\begin{array}{l}-0.84^{*} \\
(0.49)\end{array}$ \\
\hline $75^{\text {th }}$ pctile & - & $\begin{array}{l}-5.67 \\
(14.66)\end{array}$ & $\begin{array}{l}-0.14 \\
(0.12)\end{array}$ & $\begin{array}{l}2.62^{* * *} \\
(0.68)\end{array}$ & $\begin{array}{l}17.60 \\
(84.59)\end{array}$ & $\begin{array}{l}-1.74^{*} \\
(1.03)\end{array}$ & $\begin{array}{l}-0.18 \\
(0.50)\end{array}$ \\
\hline
\end{tabular}

Standard errors are in parentheses.

$* * * \mathrm{p}<0.01 ; * * \mathrm{p}<0.05 ; * \mathrm{p}<0.10$

Weighted quantile regressions with robust standard in parentheses.

Models also control for age, gender, education (high school/ged; some college; college grad; missing education), employment status, race/ethnicity, the ratio of household income to federal poverty threshold, household size, family structure (divorced/separated/widowed/never married, missing marital status), quarterly time trend, and state fixed effects. SSB stands for sugarsweetened beverages. SoFAAS stands for the solid fats, alcohol and added sugars component score of the HEI-2005. HEI-2005 stands for 2005 Healthy Eating Index.

Source: NHANES 2007-2010 
Table 7: DD Vs. DDD estimates (with Additional Interaction with Less Educated) $(n=4,148)$

\begin{tabular}{|c|c|c|c|c|c|c|c|}
\hline & & & & & & & \\
\hline & $\begin{array}{l}\text { Total } \\
\text { Energy }\end{array}$ & $\begin{array}{l}\text { SSB } \\
\text { Cal. }\end{array}$ & $\begin{array}{l}\text { Fruit-Veg } \\
\text { Cups }\end{array}$ & $\begin{array}{l}\text { Saturated } \\
\text { Fat }(\mathrm{gms}) \\
\end{array}$ & $\begin{array}{l}\text { Sodium } \\
\text { (mg) }\end{array}$ & HEI 2005 & SoFAAS \\
\hline All & $\begin{array}{l}-0.02 \\
(0.03)\end{array}$ & $\begin{array}{l}0.11 \\
(0.12)\end{array}$ & $\begin{array}{l}-0.07 \\
(0.06)\end{array}$ & $\begin{array}{l}0.02 \\
(0.05)\end{array}$ & $\begin{array}{l}-0.03 \\
(0.04)\end{array}$ & $\begin{array}{l}-0.04 * * \\
(0.02)\end{array}$ & $\begin{array}{l}-0.06 \\
(0.06)\end{array}$ \\
\hline $\begin{array}{l}\text { Parallel } \\
\text { Trends } \\
\text { (p-value) }\end{array}$ & 0.51 & 0.79 & 0.18 & 0.50 & 0.70 & 0.96 & 0.35 \\
\hline $\begin{array}{l}\text { Among } \\
\text { Less } \\
\text { Educated }^{1}\end{array}$ & $\begin{array}{l}-0.05 \\
(0.04)\end{array}$ & $\begin{array}{l}0.28 \\
(0.18)\end{array}$ & $\begin{array}{l}0.03 \\
(0.07)\end{array}$ & $\begin{array}{l}-0.02 \\
(0.06)\end{array}$ & $\begin{array}{l}-0.03 \\
(0.05)\end{array}$ & $\begin{array}{l}-0.02 \\
(0.03)\end{array}$ & $\begin{array}{l}-0.08 \\
(0.07)\end{array}$ \\
\hline $\begin{array}{l}\text { Parallel } \\
\text { Trends } \\
\text { (p-value) }\end{array}$ & 0.67 & 0.24 & 0.72 & 0.20 & 0.01 & 0.35 & 0.67 \\
\hline
\end{tabular}

Controlling for Total Energy Intake

\begin{tabular}{|c|c|c|c|c|c|c|c|}
\hline $\begin{array}{l}\text { All } \\
\text { Parallel } \\
\text { Trends } \\
\text { (p-value) }\end{array}$ & - & $\begin{array}{l}0.16 \\
(0.10) \\
0.82\end{array}$ & $\begin{array}{l}-0.08 \\
(0.06) \\
0.20\end{array}$ & $\begin{array}{l}0.05^{*} \\
(0.03) \\
0.55\end{array}$ & $\begin{array}{l}-0.004 \\
(0.03) \\
0.75\end{array}$ & $\begin{array}{l}-0.04^{* *} \\
(0.02) \\
0.95\end{array}$ & \begin{tabular}{|l}
-0.06 \\
$(0.06)$ \\
0.33
\end{tabular} \\
\hline $\begin{array}{l}\text { Among } \\
\text { Less } \\
\text { Educated } \\
\text { Parallel } \\
\text { Trends } \\
\text { (p-value) }\end{array}$ & - & $\begin{array}{l}0.38 * * \\
(0.16) \\
0.24\end{array}$ & $\begin{array}{l}0.06 \\
(0.07) \\
\\
0.80\end{array}$ & $\begin{array}{l}0.04 \\
(0.04) \\
0.69\end{array}$ & $\begin{array}{l}0.01 \\
(0.03) \\
0.00\end{array}$ & $\begin{array}{l}-0.02 \\
(0.03) \\
0.31\end{array}$ & $\begin{array}{l}-0.09 \\
(0.07) \\
\\
0.59\end{array}$ \\
\hline
\end{tabular}

Standard errors are in parentheses.

$* * * p<0.01 ; * * p<0.05 ; * \mathrm{p}<0.10$

${ }^{1}$ Dummies for SNAP-eligibility, ARRA, and SNAP*ARRA are further interacted with education category (high school and lower vs. more than high school). The table reports the triple interaction between SNAP, ARRA, and low education.

Models also control for age, gender, education (high school/ged; some college; college grad; missing education), employment status, race/ethnicity, the ratio of household income to federal poverty threshold, household size, family structure (divorced/separated/widowed/never married, missing marital status), quarterly time trend, and state fixed effects. SSB stands for sugarsweetened beverages. SoFAAS stands for the solid fats, alcohol and added sugars component score of the HEI-2005. HEI-2005 stands for 2005 Healthy Eating Index.

The percentage change is calculated as $\exp (\beta)-1$.

Source: NHANES 2007-2010 
Table 8: DD Estimates from Quantile Regressions (Additional Interaction with Less Educated) $(\mathrm{n}=4,151)$

\begin{tabular}{|c|l|l|l|l|l|l|l}
\hline & $\begin{array}{l}\text { Total Daily } \\
\text { Kcal }\end{array}$ & $\begin{array}{l}\text { SSB } \\
\text { Calories }\end{array}$ & $\begin{array}{l}\text { Fruit-Veg } \\
\text { Cups }\end{array}$ & $\begin{array}{l}\text { Saturated } \\
\text { Fat }(\mathrm{gms})\end{array}$ & $\begin{array}{l}\text { Sodium } \\
(\mathrm{mg})\end{array}$ & HEI 2005 & SoFAAS \\
\hline $25^{\text {th }}$ pctile & $\begin{array}{l}-41.21 \\
(64.97)\end{array}$ & $\begin{array}{l}0.00 \\
(4.24)\end{array}$ & $\begin{array}{l}-0.19 * \\
(0.10)\end{array}$ & $\begin{array}{l}-2.01^{* *} \\
(0.97)\end{array}$ & $\begin{array}{l}-73.61 \\
(122.75)\end{array}$ & $\begin{array}{l}-4.26^{* * *} \\
(1.21)\end{array}$ & $\begin{array}{l}-1.26^{*} \\
(0.73)\end{array}$ \\
\hline Median & $\begin{array}{l}3.77 \\
(73.08)\end{array}$ & $\begin{array}{l}25.72 * * \\
(12.97)\end{array}$ & $\begin{array}{l}-0.02 \\
(0.15)\end{array}$ & $\begin{array}{l}0.03 \\
(1.20)\end{array}$ & $\begin{array}{l}-72.73 \\
(129.49)\end{array}$ & $\begin{array}{l}1.37 \\
(1.38)\end{array}$ & $\begin{array}{l}-0.05 \\
(0.67)\end{array}$ \\
\hline $75^{\text {th }}$ pctile & $\begin{array}{l}-197.97 * * \\
(93.51)\end{array}$ & $\begin{array}{l}20.70 \\
(20.08)\end{array}$ & $\begin{array}{l}0.12 \\
(0.19)\end{array}$ & $\begin{array}{l}1.79 \\
(2.34)\end{array}$ & $\begin{array}{l}-178.03 \\
(199.51)\end{array}$ & $\begin{array}{l}0.24 \\
(1.41)\end{array}$ & $\begin{array}{l}-0.22 \\
(0.76)\end{array}$ \\
\hline
\end{tabular}

Controlling for Total Energy Intake

\begin{tabular}{|l|l|l|l|l|l|l|l}
\hline 25 & th \\
& - & 5.16 & -0.11 & $1.13^{*}$ & -68.09 & $-4.03 * * *$ & $-1.86^{* * *}$ \\
& $(5.28)$ & $(0.11)$ & $(0.69)$ & $(86.51)$ & $(1.30)$ & $(0.64)$ \\
\hline Median & - & $33.79 * *$ & 0.24 & $1.33^{*}$ & -20.56 & 0.36 & -0.41 \\
& & $(13.43)$ & $(0.15)$ & $(0.77)$ & $(89.32)$ & $(1.28)$ & $(0.59)$ \\
\hline \multirow{2}{*}{$75^{\text {th }}$ pctile } & - & 22.33 & 0.26 & $2.16^{* * *}$ & 100.98 & -0.81 & -0.33 \\
& $(17.11)$ & $(0.17)$ & $(0.84)$ & $(118.19)$ & $(1.29)$ & $(0.72)$ \\
\hline
\end{tabular}

Standard errors are in parentheses.

$* * * \mathrm{p}<0.01 ; * * \mathrm{p}<0.05 ; * \mathrm{p}<0.10$

Weighted quantile regressions with robust standard errors.

Dummies for SNAP-eligibility, ARRA, and SNAP*ARRA are further interacted with education category (high school and lower vs. more than high school). The table reports the triple interaction between SNAP, ARRA, and low education.

Models also control for age, gender, education (high school/ged; some college; college grad; missing education), employment status, race/ethnicity, the ratio of household income to federal poverty threshold, household size, family structure (divorced/separated/widowed/never married, missing marital status), quarterly time trend, and state fixed effects. SSB stands for sugarsweetened beverages. SoFAAS stands for the solid fats, alcohol and added sugars component score of the HEI-2005. HEI-2005 stands for 2005 Healthy Eating Index.

The percentage change is calculated as $\exp (\beta)-1$.

Source: NHANES 2007-2010 
Table 9: DD Estimates Excluding Midwest Region - $\left(\mathrm{n}=3,415^{1}\right)$

\begin{tabular}{|c|c|c|c|c|c|c|c|}
\hline & $\begin{array}{l}\text { Total Daily } \\
\text { Kcal }\end{array}$ & $\begin{array}{l}\text { SSB } \\
\text { Calories }\end{array}$ & $\begin{array}{l}\text { Fruit-Veg } \\
\text { Cups }\end{array}$ & $\begin{array}{l}\text { Saturated } \\
\text { Fat (gms) }\end{array}$ & $\begin{array}{l}\text { Sodium } \\
\text { (mg) }\end{array}$ & HEI 2005 & SoFAAS \\
\hline $\begin{array}{l}\text { Full } \\
\text { Parallel } \\
\text { Trends } \\
\text { (p-value) }\end{array}$ & $\begin{array}{l}-0.02 \\
(0.03) \\
0.51\end{array}$ & $\begin{array}{l}0.11 \\
(0.12) \\
0.79\end{array}$ & $\begin{array}{l}-0.07 \\
(0.06) \\
0.18\end{array}$ & $\begin{array}{l}0.02 \\
(0.05) \\
0.50\end{array}$ & $\begin{array}{l}-0.03 \\
(0.04) \\
0.70\end{array}$ & $\begin{array}{l}-0.04 * * \\
(0.02) \\
0.96\end{array}$ & $\begin{array}{l}-0.06 \\
(0.06) \\
0.35\end{array}$ \\
\hline $\begin{array}{l}\text { Excl. } \\
\text { Midwest }\end{array}$ & $\begin{array}{l}0.007 \\
(0.03)\end{array}$ & $\begin{array}{l}0.02 \\
(0.12)\end{array}$ & $\begin{array}{l}-0.07 \\
(0.07)\end{array}$ & $\begin{array}{l}0.06 \\
(0.05)\end{array}$ & $\begin{array}{l}-0.001 \\
(0.05)\end{array}$ & $\begin{array}{l}-0.04 * * \\
(0.02)\end{array}$ & $\begin{array}{l}-0.05 \\
(0.07)\end{array}$ \\
\hline $\begin{array}{l}\text { Parallel } \\
\text { Trends } \\
\text { (p-value) }\end{array}$ & 0.04 & 0.84 & 0.23 & 0.15 & 0.10 & 0.66 & 0.19 \\
\hline \multicolumn{8}{|c|}{ Controlling for Total Energy Intake } \\
\hline $\begin{array}{l}\text { Full } \\
\text { Parallel } \\
\text { Trends } \\
\text { (p-value) }\end{array}$ & - & $\begin{array}{l}0.16 \\
(0.10) \\
0.82\end{array}$ & $\begin{array}{l}-0.08 \\
(0.06) \\
0.20\end{array}$ & $\begin{array}{l}0.05^{*} \\
(0.03) \\
0.55\end{array}$ & $\begin{array}{l}-0.004 \\
(0.03) \\
0.75\end{array}$ & $\begin{array}{l}-0.04 * * \\
(0.02) \\
0.95\end{array}$ & $\begin{array}{l}-0.06 \\
(0.06) \\
0.33\end{array}$ \\
\hline $\begin{array}{l}\text { Excl. } \\
\text { Midwest } \\
\text { Parallel } \\
\text { Trends } \\
\text { (p-value) }\end{array}$ & - & $\begin{array}{l}0.05 \\
(0.12) \\
0.91\end{array}$ & $\begin{array}{l}-0.08 \\
(0.07) \\
0.37\end{array}$ & $\begin{array}{l}0.06^{* *} \\
(0.03) \\
0.41\end{array}$ & $\begin{array}{l}-0.003 \\
(0.03) \\
0.72\end{array}$ & $\begin{array}{l}-0.04 * * \\
(0.02) \\
0.71\end{array}$ & $\begin{array}{l}-0.04 \\
(0.07) \\
0.22\end{array}$ \\
\hline
\end{tabular}

Standard errors are in parentheses.

$* * * \mathrm{p}<0.01 ; * * \mathrm{p}<0.05 ; * \mathrm{p}<0.10$.

Models also control for age, gender, education (high school/ged; some college; college grad; missing education), employment status, race/ethnicity, the ratio of household income to federal poverty threshold, household size, family structure (divorced/separated/widowed/never married, missing marital status), quarterly time trend, and state fixed effects. SSB stands for sugarsweetened beverages. SoFAAS stands for the solid fats, alcohol and added sugars component score of the HEI-2005. HEI-2005 stands for 2005 Healthy Eating Index.

The percentage change is calculated as $\exp (\beta)-1$.

Source: NHANES 2007-2010 